ISSN: 0514-7336

DOI: http://dx.doi.org/10.14201/zephyrus201575125140

\title{
APORTACIÓN AL ESTUDIO DEL CASTRO DEL ALTO DE LA GARMA (CANTABRIA): LAS CERÁMICAS DE LA PRIMERA EDAD DEL HIERRO
}

\section{Contribution to the study of the Alto de La Garma hillfort (Cantabria): the pottery of the Early Iron Age}

\author{
Rafael Bolado del Castillo*, Miriam Cubas Morera*, Juan José Cepeda Ocampo**, Esteban Pereda \\ Saiz ${ }^{* * *}$, Roberto Ontañón Peredo**** y Pablo Arias Cabal* \\ * Instituto Internacional de Investigaciones Prehistóricas de Cantabria. Universidad de Cantabria. Avda. de los \\ Castros, s/n.39005 Santander. Correo-e: sebastiansanvicente@hotmail.com; mcubas.morera@gmail.com; pablo. \\ arias@unican.es \\ ** Dpto. H.a Antigua-UNED. C/ S. Martín Plaza, 4. 20570 Bergara. Correo-e: jjcepeda@euskalnet.es \\ *** Arqueólogo profesional \\ **** Museo de Prehistoria y Arqueología de Cantabria. C/ Hernán Cortés, 4. 39003 Santander. Correo-e: \\ ontanon_r@cantabria.es
}

Recepción: 4/06/2014; Revisión: 21/07/2014; Aceptación: 25/03/2015

BIBLID [0514-7336 (2015) LXXV, enero-junio; 125-140]

Resumen: El castro del Alto de La Garma (Omońo, Ribamontán al Monte) es un pequeño recinto fortificado de la Primera Edad del Hierro situado en la zona costera de Cantabria. Las excavaciones realizadas han permitido documentar una fortificación datada en el s. vir a. C., reformada en un momento posterior, en cuyo interior se levantaron estructuras habitacionales de planta circular. Dentro del registro material recuperado destaca el conjunto cerámico sobre el que se centra el siguiente trabajo.

En este artículo se presenta el análisis macroscópico del material cerámico atendiendo a sus rasgos tecnológicos, morfológicos y decorativos. Esto permitirá abordar desde bases más sólidas futuros estudios de este tipo de materiales en otros yacimientos de la región. Finalmente, se presenta una comparación del conjunto con el documentado en otros yacimientos coetáneos en la zona, destacando las similitudes o diferencias entre los materiales recuperados.

Palabras clave: Región Cantábrica; Edad del Hierro; cerámica; análisis tipológico; análisis morfológico.

Aвstract: The archaeological site of Alto de La Garma (Omoño, Ribamontán al Monte, Spain) is an early Iron Age hillfort located in the littoral of Cantabria. The excavations have documented a fortification dated to the virth century BC, rebuilt at a later time. Inside the fortified area, some circular huts have been found.

This paper presents the macroscopic analysis of the pottery ensemble focused on the technological, morphological and decorative features. That will provide a solid ground for future studies of this type of material in other sites of the region. To finish, it presents a comparison of this ensemble with the remains recorded in others contemporary archaeological sites of the area, highlighting the similarities and differences between them.

Key words: Cantabrian region; Iron Age; pottery; typological analysis; morphological analysis. 


\section{El castro del Alto de La Garma}

En la localidad de Omoño (Ribamontán al Monte), muy cerca del margen oriental de la Bahía de Santander, se halla la Zona Arqueológica de La Garma, un conjunto de yacimientos ubicados en torno al monte homónimo que fue ocupado desde el Paleolítico inferior hasta la Edad Media. El castro del Alto de La Garma se localiza en la cima de esa colina, a $186 \mathrm{~m}$ de altitud, dominando un amplio territorio que abarca la costa central de Cantabria y

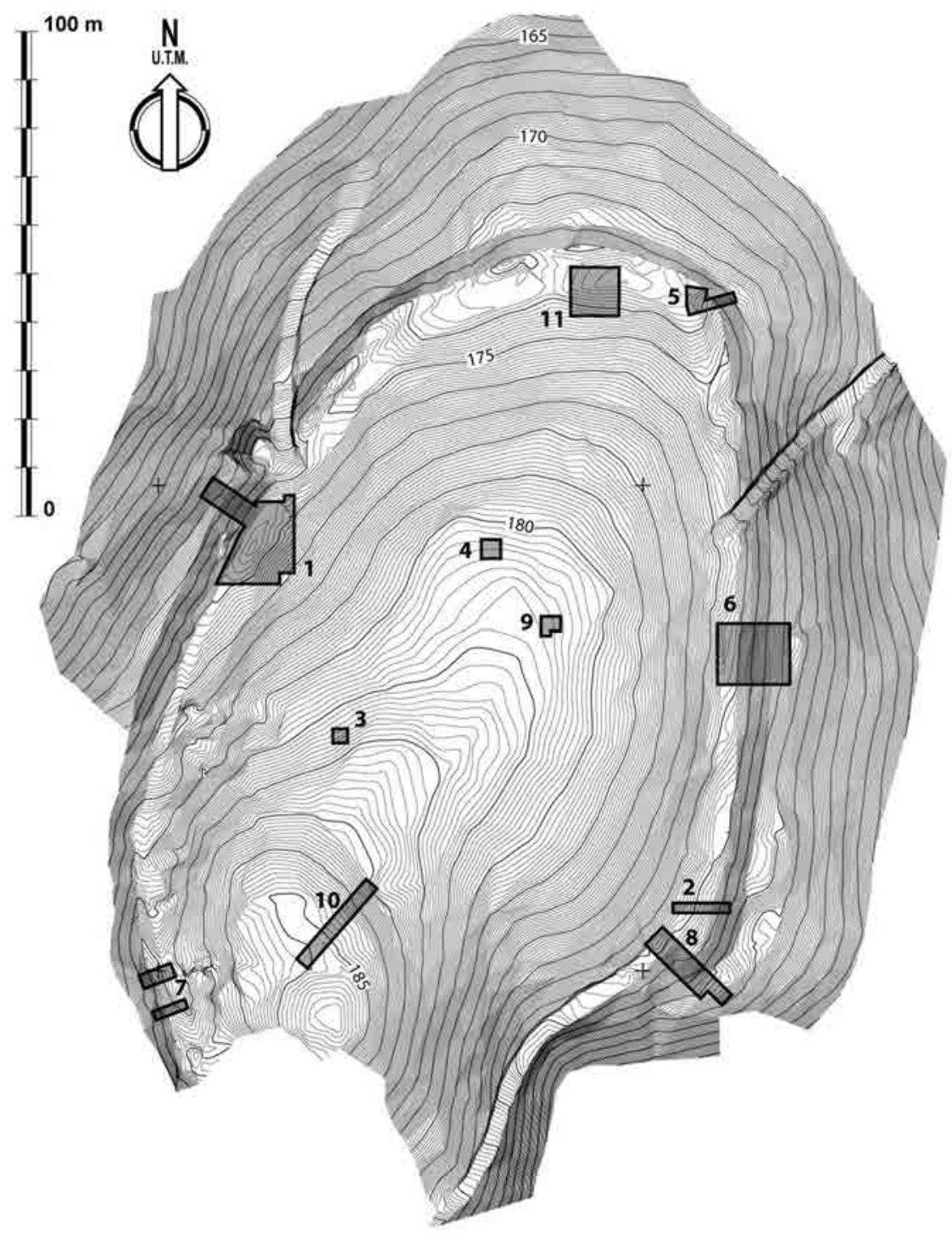

Fig. 1. Plano del castro del Alto de La Garma. los valles interiores. En su construcción se aprovecharon las condiciones naturales del lugar, lo que se manifiesta en la forma ovoide irregular que adopta su planta (Fig. 1), que abraza una superficie de $18000 \mathrm{~m}^{2}$.

Desde su descubrimiento en 1996 y hasta el año 2006 se han llevado a cabo distintas intervenciones arqueológicas que han permitido excavar 11 sectores con el objetivo de conocer su sistema defensivo y el hábitat interno (Pereda, 1999; Arias et al., 2000; Arias y Ontañón, 2008; Arias et al., 2010). En lo que respecta a las estructuras defensivas, el enclave cuenta con dos cercas pertenecientes a dos momentos constructivos distintos (Fig. 2). La más antigua consiste en un lienzo exterior de piedra, dispuesta en seco, que contuvo seguramente un terraplén interior más elevado. La segunda muralla, levantada con doble paramento de mampostería en la mayor parte de su trazado, presentaba también un aspecto ataludado. Su relleno se hizo con piedra y tierra, en una proporción que varía en función de la disponibilidad local de los materiales. Su anchura media alcanzó los $3 \mathrm{~m}$. La nueva cerca redujo ligeramente el perímetro defensivo del castro, observándose a lo largo de su desarrollo tramos en los que se levanta ex novo -sectores 6 y $7-y$ zonas donde aprovecha el lienzo exterior de la primera muralla a modo de apoyo -sector 1-. Ambas murallas probablemente estarían rematadas por una empalizada de madera.

El lugar concreto de acceso al castro es por el momento desconocido. No obstante, 
la prospección visual y la fotografía aérea han permitido observar una interrupción y engrosamiento de las defensas en el sector 8, lo que podría ocultar un entrada en esviaje protegida por al menos un bastión.

En tres de los sectores excavados intramuros se han documentado restos de varias estructuras de habitación. A pesar de su mal estado de conservación se ha podido comprobar que se trata de construcciones de planta ovoide, de entre 6 y $7 \mathrm{~m}$ de diámetro, adosadas a las murallas o muy próximas a ellas. Todas cuentan

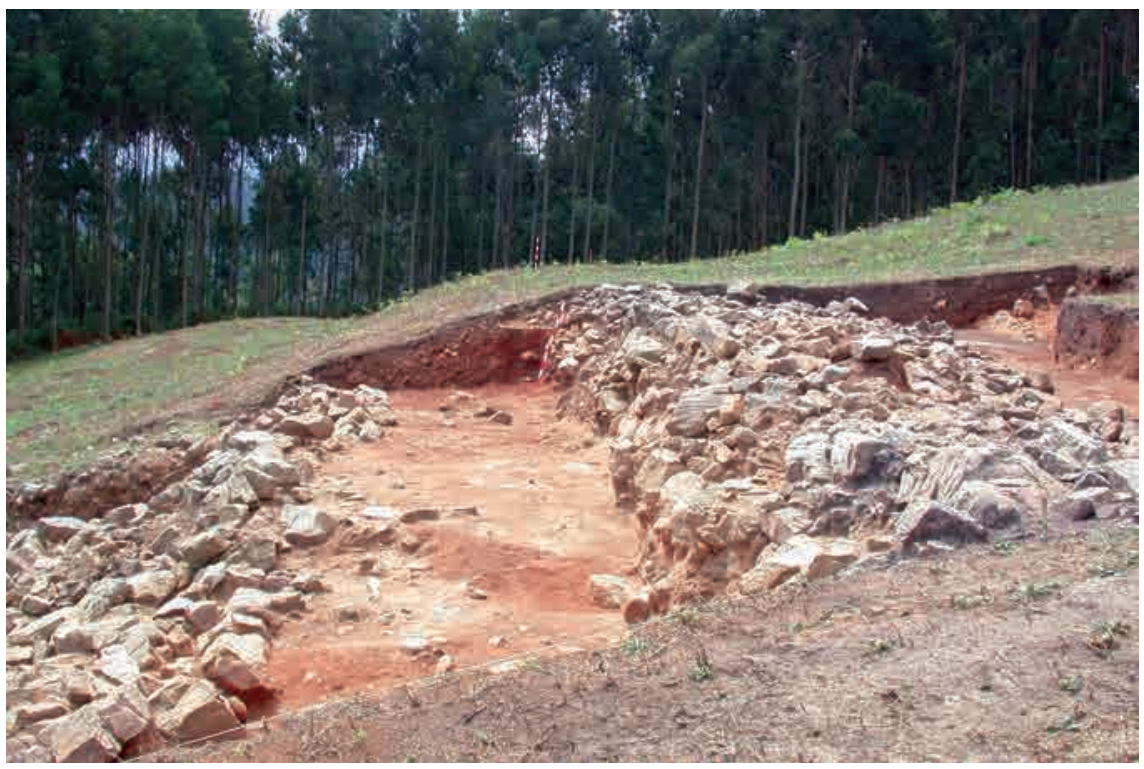
con zócalos de piedra sobre

FIG. 2. Sector 6 con las dos murallas.

los que se habrían dispuesto

postes de madera y entramado de zarzo recubierto con manteado de barro. De este material se han recuperado numerosos fragmentos en la excavación. Es probable que la techumbre estuviera construida con elementos orgánicos.

Entre las estructuras de habitación excavadas hay que destacar la identificada en el sector 1 (Fig. 3), tanto por su estado de conservación como por haber proporcionado la única datación por $\mathrm{C}^{14} \mathrm{ac}$ tualmente disponible. Se trata de una cabaña delimitada por un zócalo, compuesto por dos hiladas de piedra arenisca, asentado directamente sobre la roca madre y coetáneo al primer recinto defensivo. En torno al pequeño arco de círculo que se conserva, que delimitaba una cabaña de aproximadamente siete metros de diámetro, se recuperaron restos de mineral de hierro, escorias y cerámica, además de una pequeña concentración de cereal que incluía restos de Hordeum vulgare y Triticum sp. Son estas semillas las que han proporcionado una datación radiocarbónica de $2475 \pm 45$ BP (AA-45565, correspondiente al intervalo $757-538 \mathrm{cal} \mathrm{BC}$ con $68,2 \%$ de probabilidad, según la curva IntCal13, procesada con el programa OxCal 4.2.3) (Bronk Ramsey, 2009; Reimer et al., 2013) que, por asociación directa, permite situar entre los ss. VII-VI a. C. la construcción de la cabaña e, igualmente, proponer la misma cronología para la primera muralla. La formación de un podsol entre ésta y la segunda obra defensiva parece indicar un lapso de tiempo no inferior a un siglo para su erección (Arias et al., 2010).

El registro material procedente del castro del Alto de La Garma está compuesto por un total de 2126 piezas, de las cuales un 54\% -1148 fragmentos- lo compone el conjunto cerámico y un $34 \%-723$ fragmentos- restos de manteado de barro que debemos relacionar con las estructuras de hábitat. La actividad metalúrgica se manifiesta a través de algunos restos de escoria y mineral de hierro, un regatón, una lezna de bronce, un posible talón de hacha de anillas, así como tres fragmentos pertenecientes a un crisol con restos de fundición de base cobre. Junto a la posible evidencia de actividad agrícola proporcionada por los restos de cereal mencionados más arriba, cabe reseñar la información proporcionada por la fauna, compuesta por Ovis aries/Capra hircus, Bos taurus y Cervus elaphus.

No disponemos de información detallada en lo que respecta al abandono del castro. La ausencia de materiales atribuibles a la Segunda Edad del Hierro sugiere que este hecho se habría producido en el curso de la segunda mitad del I milenio a. C. 


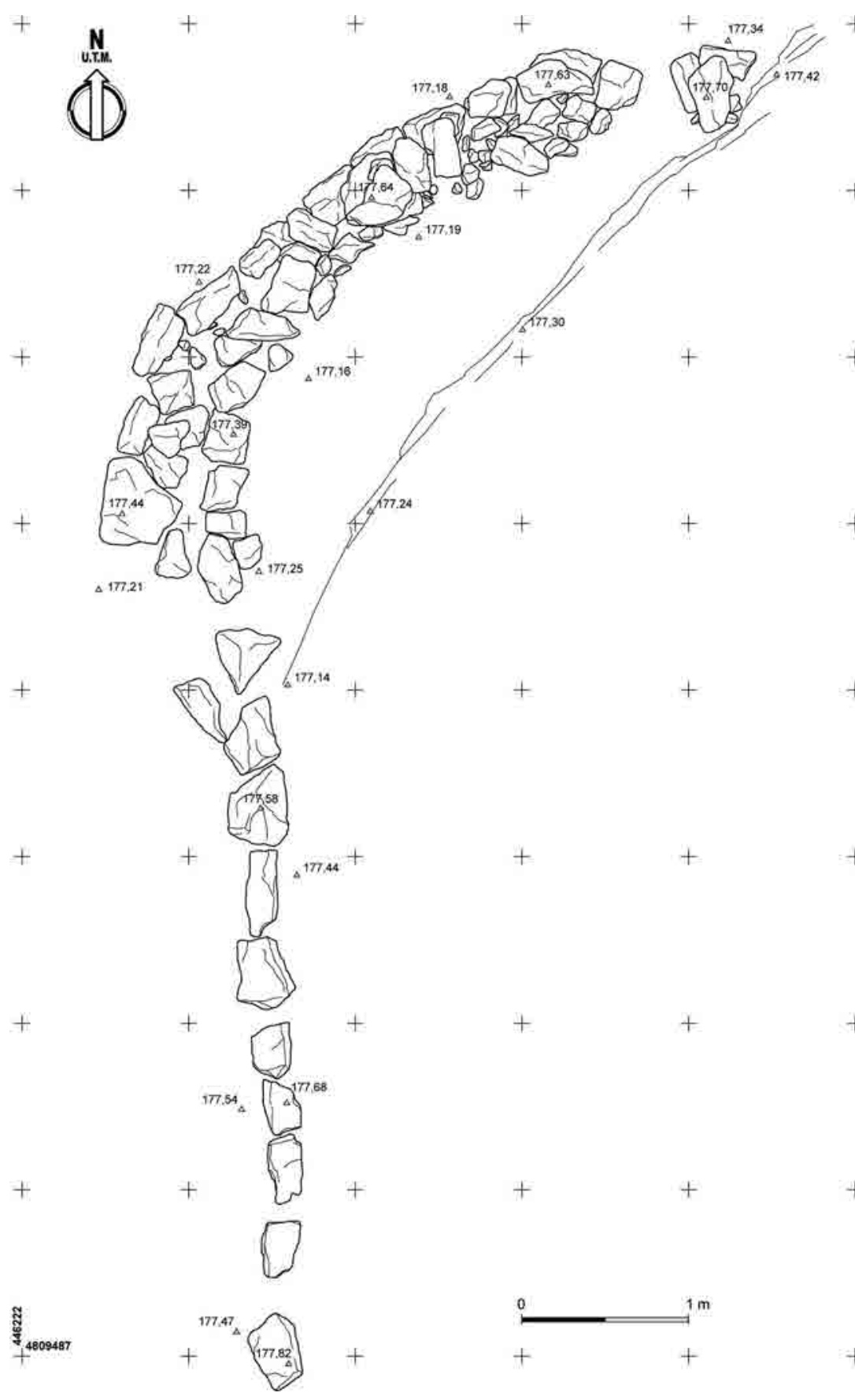

Fig. 3. Cabaña del sector 1. $+\quad$ a los aspectos técnicos, tecnológicos, morfológicos y decorativos. Esta primera aproximación se basa en la caracterización macroscópica del conjunto ce-

+ rámico, entendiendo como tal ..."aquella que se efectúa sobre la pieza o el fragmento cerámi$c o$, sin que requiera una preparación específica de la muestra”... (Calvo et al., 2004). La definición y descripción de los rasgos observados en cada fragmento cerámico permite una clasificación inicial que luego se completa con la ayuda de la microscopia óptica binocular.

En general, la cerámica prehistórica se caracteriza por una gran variabilidad tecnológica y un elevado índice de fragmentación, lo que supone una notable dificultad para identificar recipientes o perfiles completos. Dadas las características generales del conjunto, se ha optado por seleccionar el fragmento como unidad de análisis, de manera que se ha procedido a la descripción individualizada de todos los fragmentos cerámicos documentados durante las intervenciones arqueológicas. El material se ha descrito atendiendo a las siguientes categorías:

- Contexto: esta categoría recoge las informaciones de campo que permiten la atribución del fragmento al contexto estratigráfico de procedencia. Se han especificado la unidad estratigráfica, las coordenadas, el número de inventario y la sigla, así como la referencia de los planos y fotografías in situ.

\section{Metodología de estudio del material cerámico}

El análisis del conjunto cerámico procedente del Alto de La Garma se ha realizado atendiendo
- Tamaño de los fragmentos: el tamaño de los fragmentos cerámicos se ha definido por sus tres dimensiones mensurables (mm). El cálculo de estas 
dimensiones se ha basado en la orientación del fragmento dentro del recipiente del que procede. En el caso de los fragmentos que no se pueden orientar, se ha escogido como longitud la medida máxima, mientras que como anchura se ha establecido la mínima. Estas mediciones se han modificado ligeramente en el caso de las bases, en las que se ha considerado longitud la altura con respecto al plano horizontal de apoyo, mientras que la anchura se mantiene como en el resto de fragmentos.

- Rasgos técnicos y tecnológicos: el estudio de los aspectos técnicos, desde el punto de vista macroscópico, se ha centrado en la identificación de las inclusiones no plásticas (determinación de su naturaleza e identificación), las técnicas de elaboración, los tratamientos superficiales y la estimación de la atmósfera de cocción. Las técnicas de elaboración se han inferido a partir de las macrotrazas tecnológicas observables en las superficies cerámicas (Rye, 1994).

Por su parte, la determinación del tipo de atmósfera de cocción se ha realizado a partir de la gama cromática observada en el fragmento (Rice, 1987). Sin embargo, debemos apuntar que tal inferencia presenta ciertas limitaciones ya que el color de la cerámica se encuentra también relacionado con otros aspectos como las inclusiones no plásticas, la composición química de la arcilla, el tipo de combustible empleado en su cocción y la incidencia de los procesos postdeposicionales.

- Rasgos morfológicos: en un estudio basado en fragmentos y no en vasijas completas es necesario precisar a qué parte morfológica pertenecen aquellos. Las categorías distinguidas en este caso han sido borde, cuello, galbo, base y elementos complementarios, entendiendo como tales los asideros. Se ha incluido también un grupo de indeterminados para las piezas en las que el pequeño tamańo o la mala conservación impiden adscribirlas a las categorías anteriores.

- Rasgos decorativos: con respecto a las técnicas decorativas se han especificado diversos aspectos relacionados con la técnica de ejecución, la ubicación de la decoración y los motivos representados. En la descripción de los motivos decorativos es importante especificar la superficie en la que se encuentra. Por último, se han descrito los motivos representados que pueden ser lineales, geométricos, en espiga, antropomorfos, vegetales o fitomorfos, zoomorfos, etc.

\section{Las manufacturas cerámicas del Alto de La Garma}

\subsection{Configuración general del conjunto}

Como ya adelantamos, el conjunto cerámico procedente del castro del Alto de La Garma está compuesto por 1148 fragmentos, distribuidos de forma bastante heterogénea en las zonas excavadas (Fig. 4).

Todos los niveles, en mayor o menor medida, aportan alguna evidencia cerámica; sin embargo, se aprecian acumulaciones significativas que se deben poner en relación con la ocupación del yacimiento y con el segundo momento constructivo. De esta forma podemos ver como los niveles de ocupación $3 \mathrm{y}$ 4 del sector 1 , asociados a los cereales mencionados más arriba y a la estructura habitacional, aportan 388 restos; en los sectores 7 y $7 \mathrm{~b}$ por su parte, centrados en la excavación de un tramo de muralla, se documentan 112 y 38 fragmentos respectivamente, de los cuales 96 fragmentos proceden del nivel 3, el relleno de la muralla (Fig. 5). Este hecho en concreto nos permite corroborar la existencia de ese segundo momento constructivo que redujo el perímetro del castro y modificó la defensa original, aprovechando materiales de la primera ocupación, ahora quizás extramuros, para rellenar la nueva defensa.

\begin{tabular}{|c|c|c|}
\hline $\begin{array}{c}\text { Sector } \\
\text { De Excavación }\end{array}$ & $\begin{array}{c}\text { Número } \\
\text { De Restos }\end{array}$ & PorcentaJe \\
\hline 1 & 796 & $69,4 \%$ \\
\hline 2 & 3 & $0,26 \%$ \\
\hline 3 & 0 & $0,00 \%$ \\
\hline 4 & 1 & $0,09 \%$ \\
\hline 5 & 75 & $6,50 \%$ \\
\hline 6 & 82 & $7,14 \%$ \\
\hline 7 & 112 & $9,75 \%$ \\
\hline $7 \mathrm{~B}$ & 38 & $3,31 \%$ \\
\hline 8 & 15 & $1,30 \%$ \\
\hline 9 & 5 & $0,43 \%$ \\
\hline Superficial & 21 & $1,82 \%$ \\
\hline TotaL & 1148 & $100 \%$ \\
\hline
\end{tabular}

FIG. 4. Distribución del conjunto cerámico en función de su contexto de procedencia. 


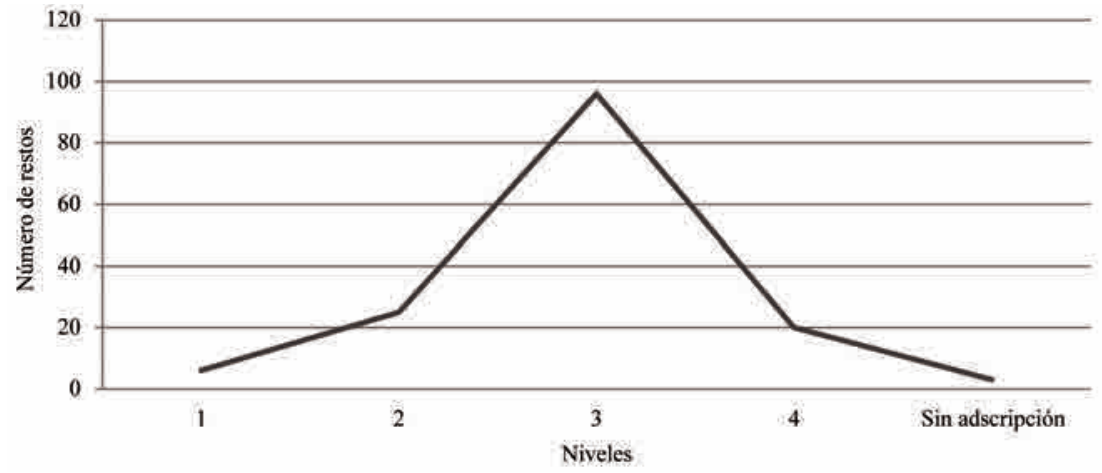

FIG. 5. Número de fragmentos y niveles arqueológicos en los sectores 7 y 76 . presencia de distintos tipos de inclusiones no plásticas de naturaleza mineral de carácter carbonatado -calcita- y silíceo -cuarzo- (Fig. 7). Únicamente se han observado fragmentos de roca de textura ofítica en uno de los fragmentos.

El tamaño, la morfología y la elevada recurrencia de algunos minerales, como la calcita, nos han llevado a plantear la hipótesis de una posible adición intencional, es decir, de su posible uso como desgrasante. Su identificación estaría reflejando

La cerámica se caracteriza por un elevado índice de fragmentación y por el pequeño tamaño de los fragmentos, cuyas dimensiones máximas alcanzan $116,78 \mathrm{~mm}$ de longitud, con una media de 20,3 $\pm 9,08 \mathrm{~mm}$ y $117 \mathrm{~mm}$ de anchura máxima con una media de 16,9 $\pm 9,14 \mathrm{~mm}$. No se han identificado recipientes completos ni perfiles reconstruibles.

\subsection{Rasgos tecnológicos}

Los fragmentos presentan un grosor medio de $7,44 \pm 2,11 \mathrm{~mm}$, debiéndose precisar que en su cálculo únicamente se han considerado los fragmentos que conservan ambas superficies y que, por tanto, permiten calcular el grosor real $-\mathrm{N}=702-$. $\mathrm{Si}$ atendemos a las partes morfológicas (Fig. 6), se observa una cierta similitud, exceptuando las bases que presentan un grosor mayor. El análisis tecnológico realizado mediante lupa binocular refleja la

\begin{tabular}{|l|c|c|c|}
\hline $\begin{array}{c}\text { Parte } \\
\text { MorfológICA }\end{array}$ & $\begin{array}{c}\text { Número } \\
\text { DE Restos }\end{array}$ & $\begin{array}{c}\text { Media } \\
\text { ARITMÉTICA } \\
(\mathrm{mm})\end{array}$ & $\begin{array}{c}\text { DesviaCión } \\
\text { TípICA }\end{array}$ \\
\hline Borde & 62 & 9,94 & 3,77 \\
\hline Base & 16 & 10,53 & 3,26 \\
\hline Cuello & 17 & 8,05 & 2,12 \\
\hline Galbo & 541 & 7,09 & 1,50 \\
\hline Indeterminada & 66 & 7,08 & 1,68 \\
\hline TOTAL & 702 & & \\
\hline
\end{tabular}

FIG. 6. Grosor medio en función de las distintas partes morfológicas. una modificación intencional de las arcillas con la finalidad de alterar sus características físico-químicas para obtener un producto cerámico con unas determinadas propiedades.
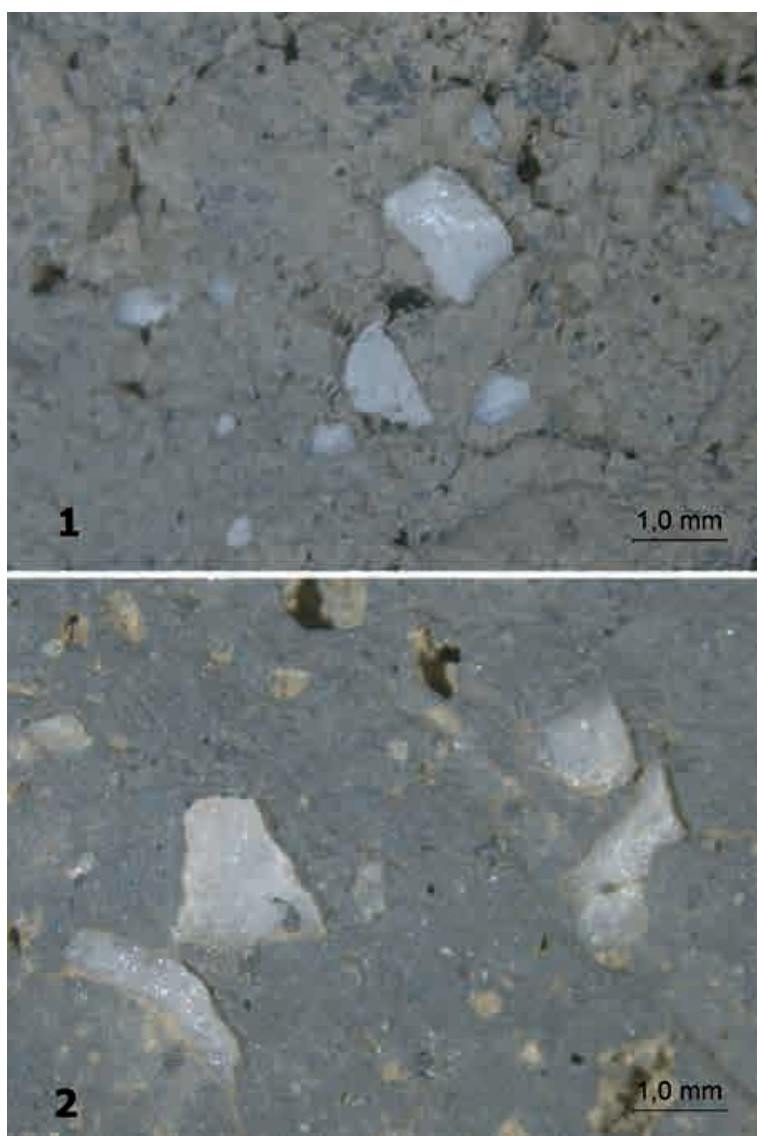

FIG. 7. Inclusiones no plásticas de calcita (1) y cuarzo (2). 


\begin{tabular}{|c|c|c|c|c|c|c|c|c|c|}
\hline \multicolumn{10}{|c|}{ Tratamiento Superficial Exterior } \\
\hline Alisado & Alisado-Raspado & Bruñido & Raspado & Espatulado & Sin tratamiento & Regularizado & Inapreciable & No se conserva & TOTAL \\
\hline 22 & 0 & 1 & 1 & 0 & 442 & 423 & 6 & 253 & 1148 \\
\hline \multicolumn{10}{|c|}{ Tratamiento de Superficie InTERIOR } \\
\hline Alisado & Alisado-Raspado & Bruñido & Raspado & Espatulado & Sin tratamiento & Regularizado & Inapreciable & No se conserva & TOTAL \\
\hline 23 & 1 & 1 & 2 & 1 & 447 & 385 & 10 & 278 & 1148 \\
\hline
\end{tabular}

FIG. 8. Tratamientos superficiales.

Las cerámicas presentan en general una textura porosa, debido fundamentalmente a los procesos de alteración postdeposicional. En muchos casos se han observado procesos de disolución, especialmente de aquellos de naturaleza carbonatada. La disolución de la calcita se observa de forma preferente en la superficie de los fragmentos y podría estar relacionada con su enterramiento en un medio ácido, con las acciones de lixiviado debido a la pluviosidad o con la actividad hídrica del suelo (Olaetxea, 2000). Este tipo de alteraciones postdeposicionales se documenta en otras cerámicas de la Edad del Hierro del norte peninsular, por ejemplo en el País Vasco (Olaetxea, 2000), ya que en su mayoría proceden de contextos al aire libre y se encuentran afectadas por las acciones mencionadas anteriormente.

Con la excepción de cuatro fragmentos procedentes de la recogida superficial, las trazas observadas en la superficie de los fragmentos reflejan manufacturas realizadas a mano. Ello supone, por

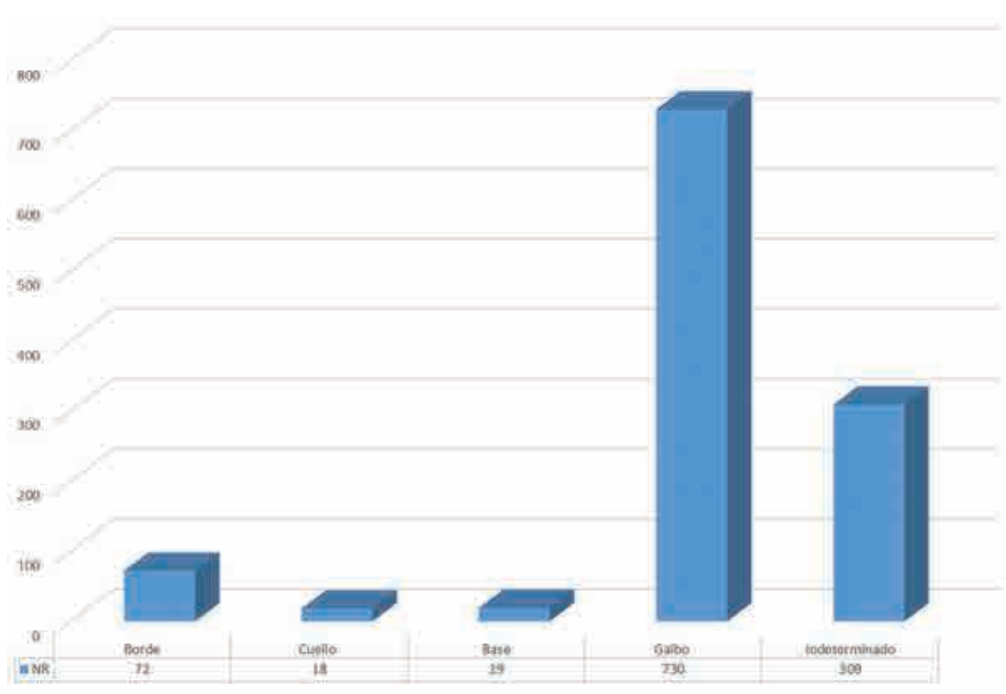

Fig. 9. Partes morfológicas. tanto, que nos encontramos ante un conjunto elaborado casi en su totalidad en un momento previo a la introducción del torno en Cantabria, cuyos primeros indicios se datan en el s. III cal BC (Cubas et al., 2013). Este aspecto posiblemente esté relacionado con la extrema escasez de la cocción oxidante $-0,6 \%$ - y el predominio de la cocción alternante $-77,38 \%$ - y reductora $-22,01 \%$ -

Las trazas tecnológicas relacionadas con los tratamientos superficiales son muy escasas. La mayor parte del conjunto carece de tratamiento superficial, y entre estos el más frecuente es la regularización de ambas superficies $-36,7 \%$ en la exterior y $33,4 \%$ en la interior-. Un análisis pormenorizado de estas trazas refleja que el tratamiento superficial más abundante es el alisado, tanto en el exterior como en el interior del recipiente $-1,99 \%$ para ambos-, que, en ocasiones, se combinan en la misma vasija. Marginalmente se documenta el bruñido $-0,08 \%$ en ambas superficies-, el raspado $-0,08 \%$ para la superficie exterior y $0,25 \%$ para la interior-, el espatulado $-0,08 \%$ para la interior- o la combinación de raspado y alisado $-0,08 \%$ en la superficie interior- (Fig. 8).

\subsection{Rasgos morfológicos}

Aunque, como señalábamos antes, no ha sido posible documentar ningún perfil ni morfología completa, sí se ha podido reconocer un cierto número de fragmentos morfológicamente representativos, entendiendo como tal bordes, cuellos y bases (Fig. 9). Entre estos destaca la presencia de los fragmentos de borde, que constituyen un $6,2 \%$ del conjunto y presentan mayoritariamente una direccionalidad exvasada y recta, con un predominio de 

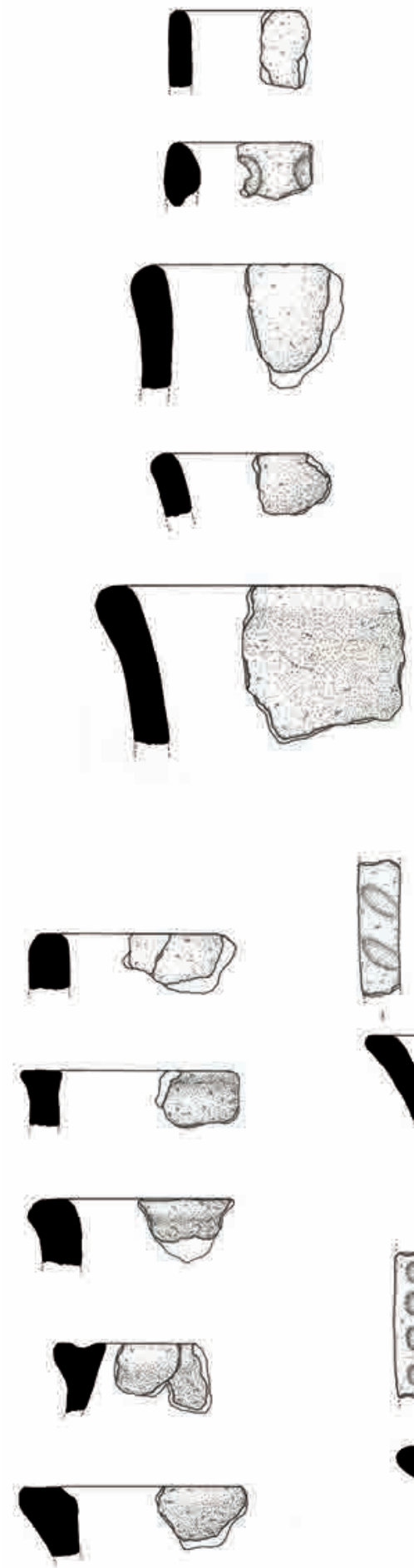

2
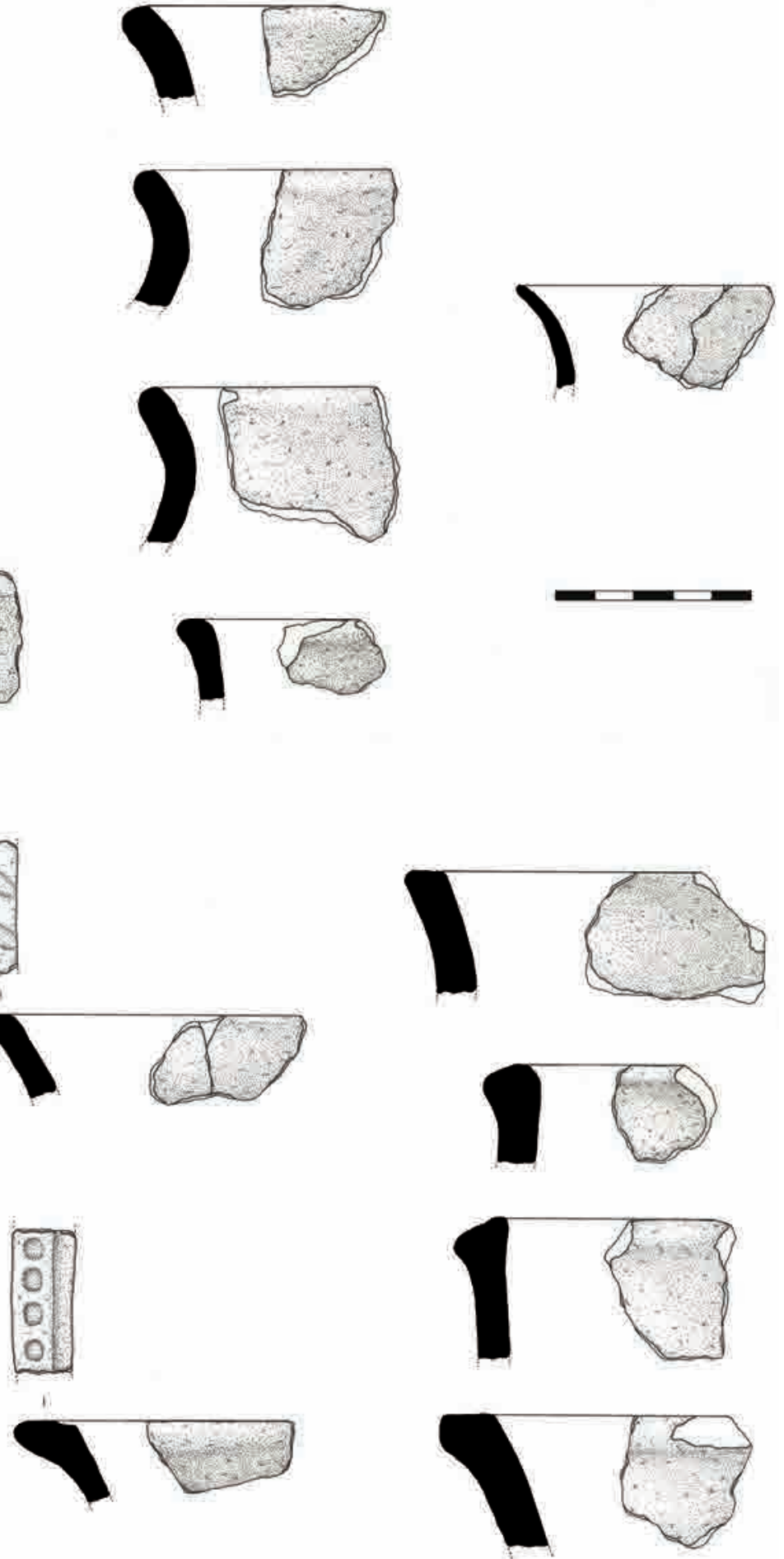

FIG. 10. Morfología de los bordes. 

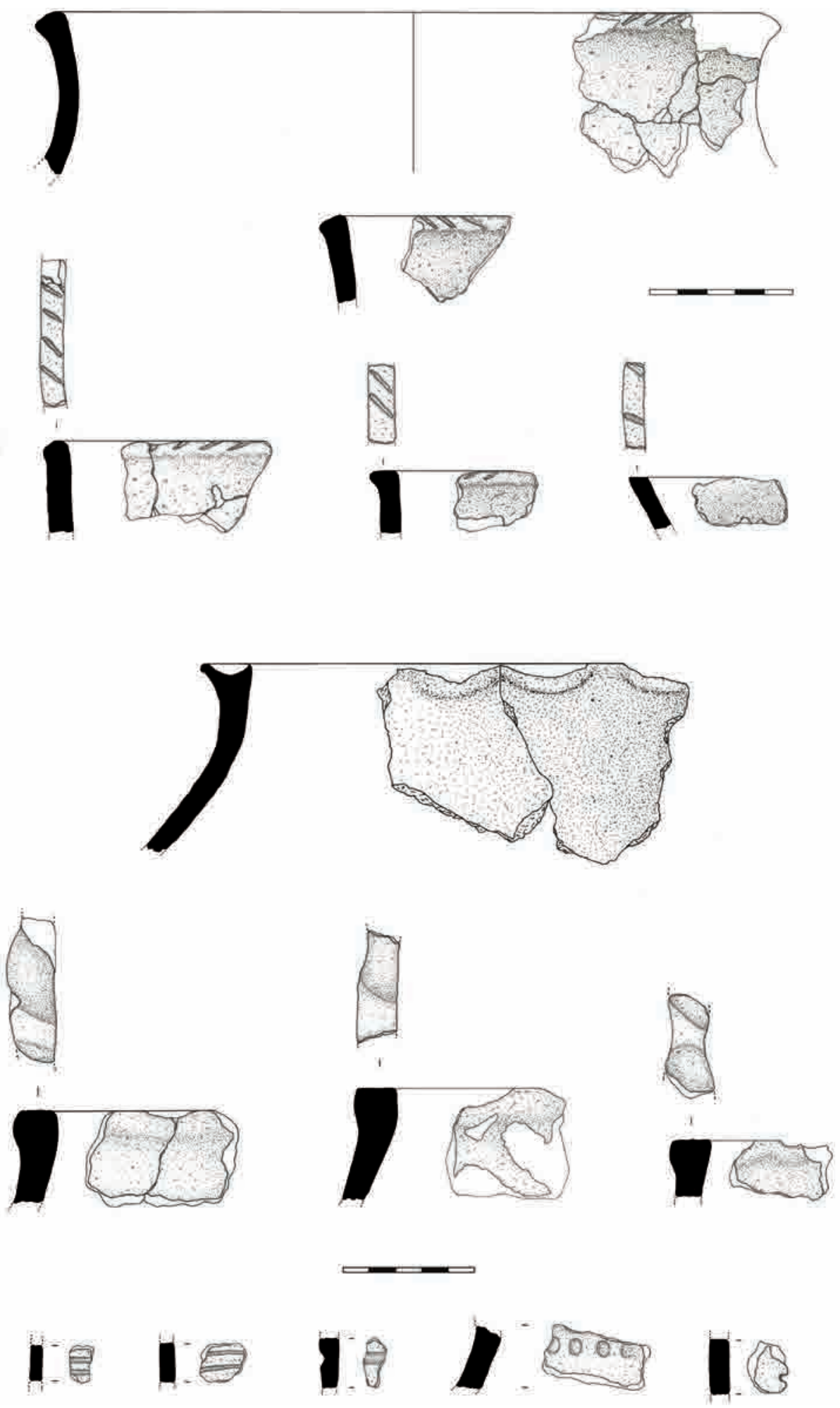

Fig. 11. Motivos decorativos documentados en el conjunto cerámico. 


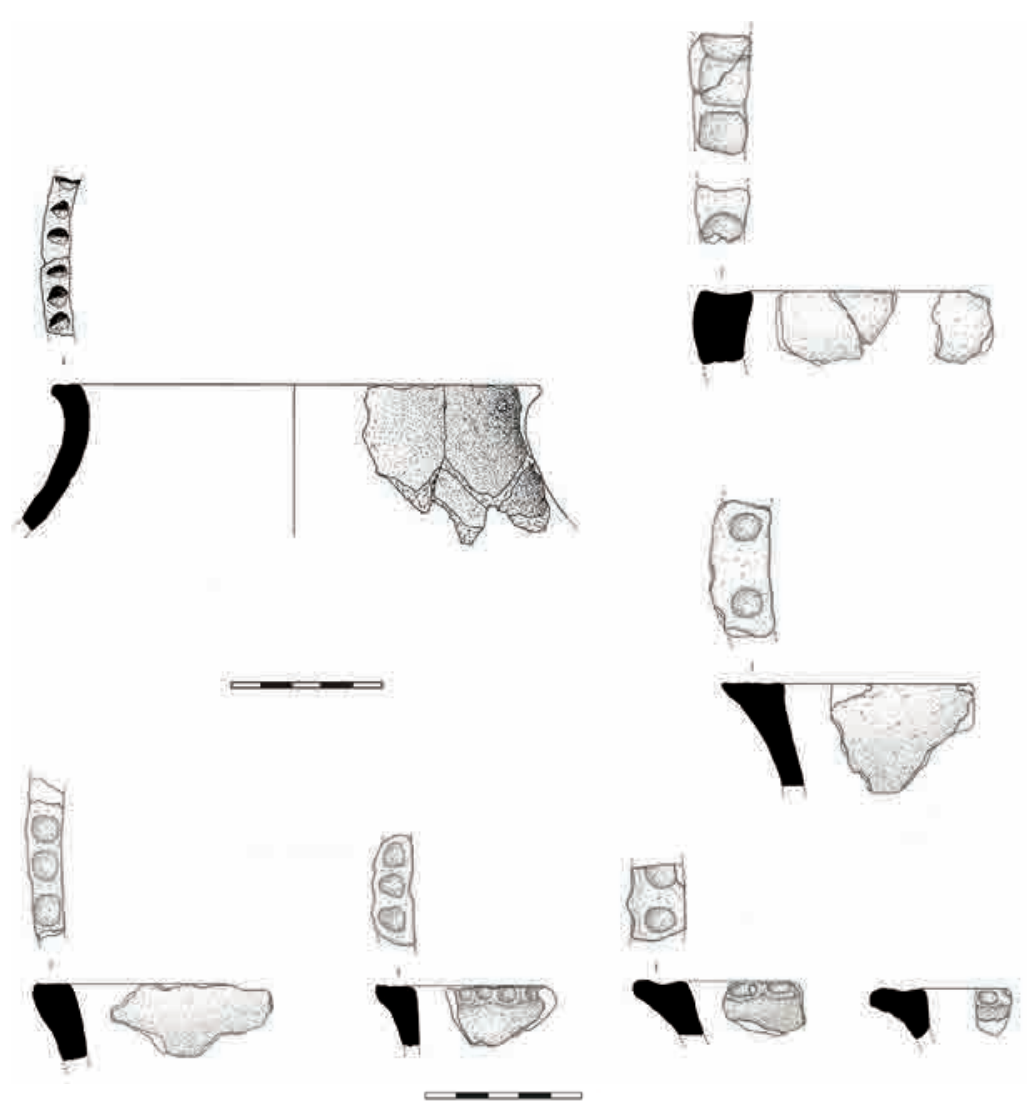

Fig. 12. Motivos decorativos documentados en el conjunto cerámico.
Hay una total ausencia de elementos de prensión, entendiendo como tales asas, mamelones y mangos.

\subsection{Rasgos decorativos}

Las decoraciones constituyen un escaso porcentaje dentro del conjunto cerámico analizado -3,37\%-. En todos los casos se localizan en la superficie exterior de los fragmentos, observándose un predominio de las decoraciones realizadas en los bordes $-79,4 \%-$ (Figs. 10-12). Las técnicas decorativas documentadas son la impresión y la incisión y, en un único caso, la combinación de ambas. La impresión -56,4\%- está realizada mayoritariamente a partir de digitaciones, exceptuando un único ejemplo de ungulación, mientras que la incisión $-41,02 \%$ - se caracteriza por sencillos motivos lineales.

Son especialmente significativas las decoraciones que aparecen sobre el labio de los bordes, alcanzando un $66,6 \%$ del total de fragmentos decorados. Se trata las morfologías engrosadas, planas y redondeadas convexas. De todos ellos únicamente dos nos han permitido conocer el diámetro de la boca, 16 y $25 \mathrm{~cm}$ respectivamente (Figs. 10-12).

En cuanto a la parte inferior de los recipientes cerámicos, únicamente podemos precisar cómo es la morfología de las bases. En todos los casos se trata de bases planas, de perfil recto y ondulado $-78,90 \%$ y $10,55 \%$ respectivamente- y únicamente en dos casos se pueden considerar bases planas indicadas $-10,55 \%$-. Cabe señalar una de las bases que aparece decorada en su exterior mediante una línea de digitaciones paralela a la superficie de apoyo (Fig. 13).
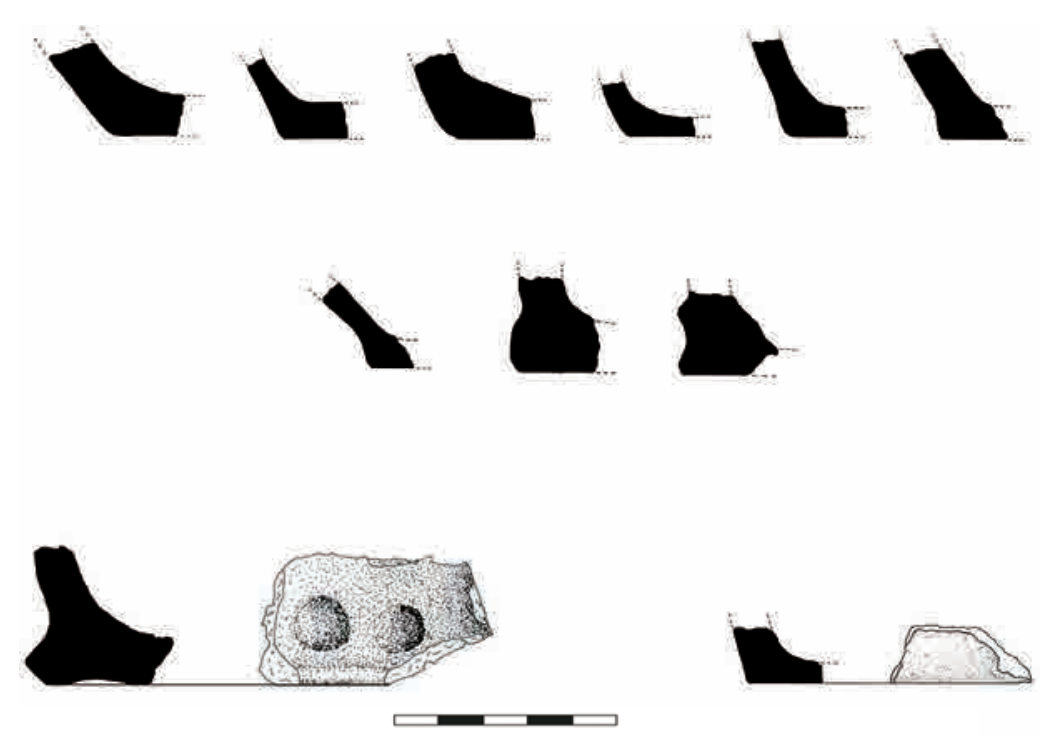

Fig. 13. Morfología de los fragmentos de base. 
fundamentalmente de digitaciones o ungulaciones seriadas $-38,4 \%$-, motivos lineales incisos oblicuos $-25,6 \%-$ y uno múltiple (Figs. 14-15).

\begin{tabular}{|c|c|c|c|c|c|}
\hline & \multicolumn{4}{|c|}{ Motivos Decorativos } & \multirow{2}{*}{ TotaL } \\
\cline { 2 - 5 } & Digitaciones & Ungulaciones & $\begin{array}{c}\text { Incisiones } \\
\text { lineales }\end{array}$ & $\begin{array}{c}\text { Digitaciones e } \\
\text { incisiones lineales }\end{array}$ & \\
\hline $\mathrm{N}$ & 18 & 1 & 19 & 1 & 39 \\
\hline
\end{tabular}

FIG. 14. Decoraciones.

\subsection{Función}

Generalmente, los estudios de funcionalidad se basan en la morfología de los recipientes o en la realización de análisis de residuos. En el caso de la cerámica del Alto de La Garma no se han podido reconstruir perfiles completos que permitan realizar una inferencia sobre la funcionalidad a la que estuvo destinada el recipiente. No obstante, se ha podido determinar una función concreta, su uso como crisol, a partir de tres fragmentos que conservan evidencias de fundición en la superficie interior (Fig. 16).

\section{La cerámica durante la Primera Edad del Hierro en Cantabria}

El estado actual de la investigación referida a la Primera Edad del Hierro en Cantabria $y$, en concreto, a la producción cerámica, es poco menos que embrionario. Una limitación

\begin{tabular}{|l|c|c|c|c|}
\hline LoCALIZACIÓN & \multicolumn{3}{|c|}{ TIPO DE DECORACIÓN } & TOTAL \\
\hline & Impresión & Incisión & Impresión e incisión & \\
\hline Borde exterior & 4 & 1 & 0 & 5 \\
\hline Borde labio & 15 & 10 & 1 & 26 \\
\hline Galbo & 2 & 5 & 0 & 7 \\
\hline Base & 1 & 0 & 0 & 1 \\
\hline TotaL & 22 & 16 & 1 & 39 \\
\hline
\end{tabular}

FIg. 15. Localización de las decoraciones.

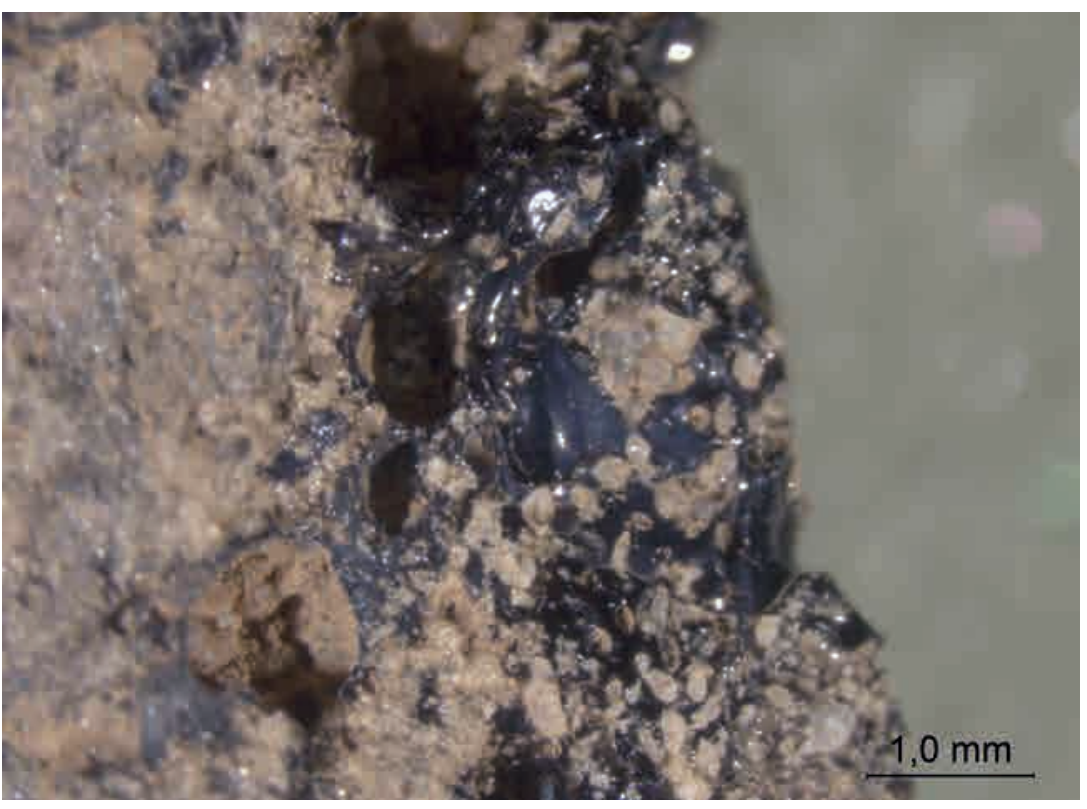

FIG. 16. Crisol. casi insalvable es la que se deriva de la escasez de hallazgos, pues sólo contamos con los datos procedentes de los yacimientos de Argüeso-Fontibre (Campoo de Suso) y Castilnegro (Medio de Cudeyo-Liérganes), además del caso que aquí presentamos.

Como sucede en el Alto de La Garma, en ambos enclaves el conjunto cerámico se caracteriza por un elevado índice de fragmentación. En el caso del castro de Argüeso-Fontibre son manufacturas a mano, entre las que se identifican ollas, pequeños

cuencos y vasos de paredes delgadas, junto a ollas de almacenaje. Los bordes presentan morfologías muy similares a las identificadas en el Alto de La Garma, con direccionalidad recta o ligeramente exvasada y morfologías planas, engrosadas o redondeadas. Las bases son planas y entre las técnicas decorativas se documentan las impresiones digitadas o unguladas (Ruiz, 1999, 2000, 2007, 2010, 2011; Van den Eynde, 2000) (Fig. 17). 


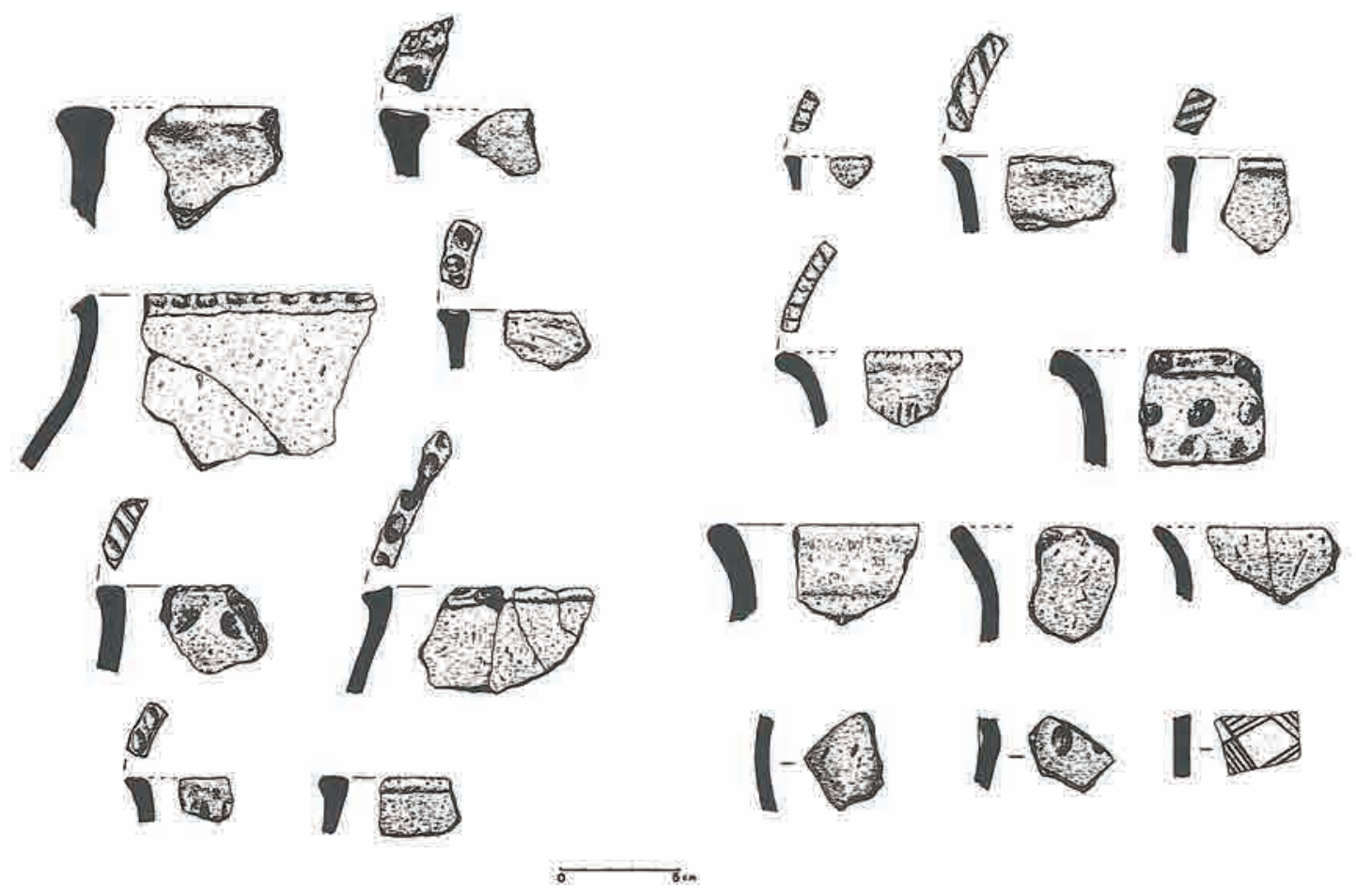

1
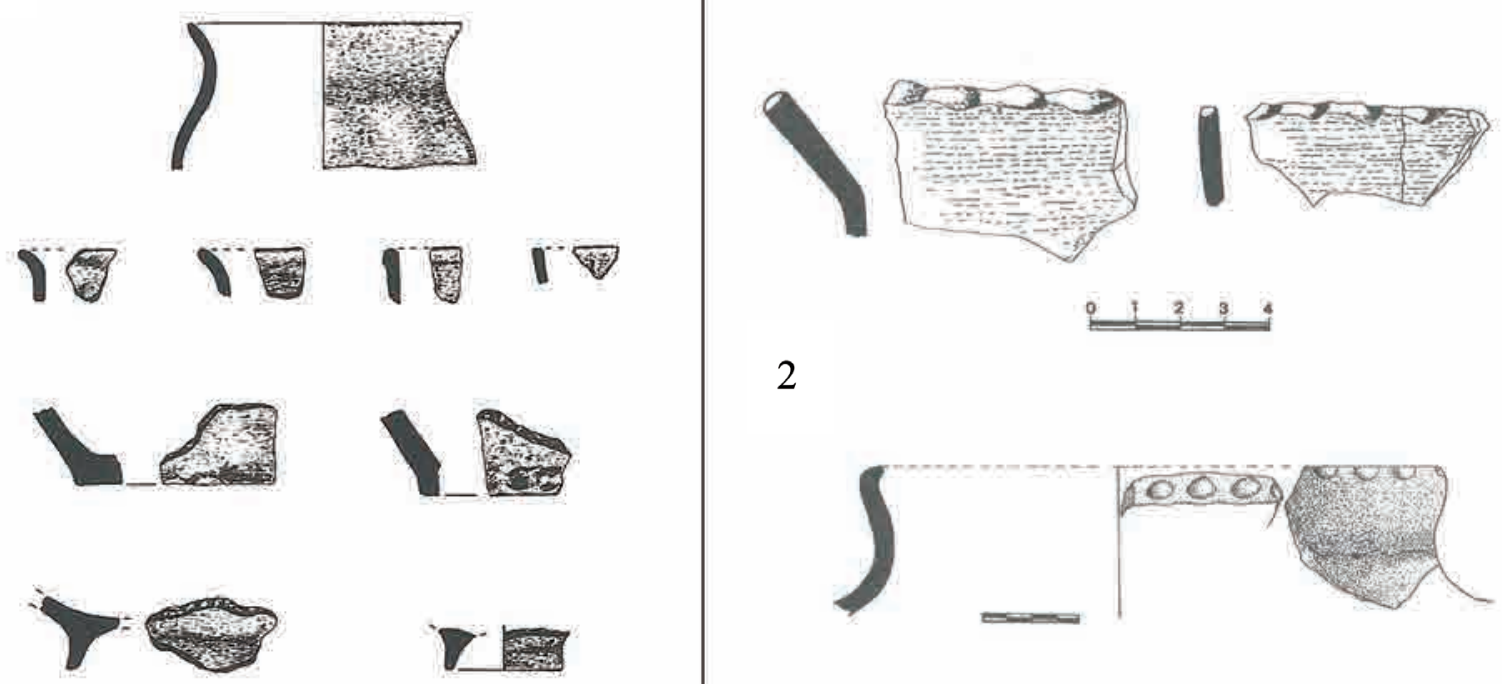

2

FIG. 17. Cerámica: 1) del castro de Argüeso-Fontibre y 2) del yacimiento del Ostrero (según Ruiz, 1999, 2010 y Lamalfa et al., 1996).

El castro de Castilnegro incluye entre sus materiales un conjunto importante de cerámicas realizadas a mano. Las pastas son groseras, de textura porosa y se menciona el uso del desgrasante vegetal, si bien esto último puede ser una apreciación realizada a partir de la observación de las vacuolas dejadas en los recipientes por la disolución de los desgrasantes de calcita, tan característica de los terrenos 
ácidos y lavados en los que han aparecido estos materiales (Olaetxea, 2000). En este yacimiento se observan morfologías distintas, tales como las ollas globulares, de perfil en $S$ con bordes rectos y planos. Tipológicamente se ha identificado una serie de recipientes muy abiertos, interpretados como platos o fuentes, que no aparecen en el resto de yacimientos (Valle, 2000, 2008, 2010; Valle y Serna, 2003; Fernández Acebo et al., 2004). Entre las técnicas decorativas se identifican la impresión -digitaciones en los bordes y ungulaciones en los galbosy las incisiones oblicuas que aparecen en el resto de contextos (Figs. 18-19).

Debemos destacar, por último, los restos hallados en el yacimiento al aire libre de El Ostrero (Maliaño), donde se documentan algunas piezas similares a las citadas (Lamalfa et al., 1996). Se trata de tres bordes de factura manual y tendencia exvasada que conservan una decoración ungulada en el labio (Fig. 17). Una característica que nos lleva a pensar en su ocupación durante la primera mitad del I milenio
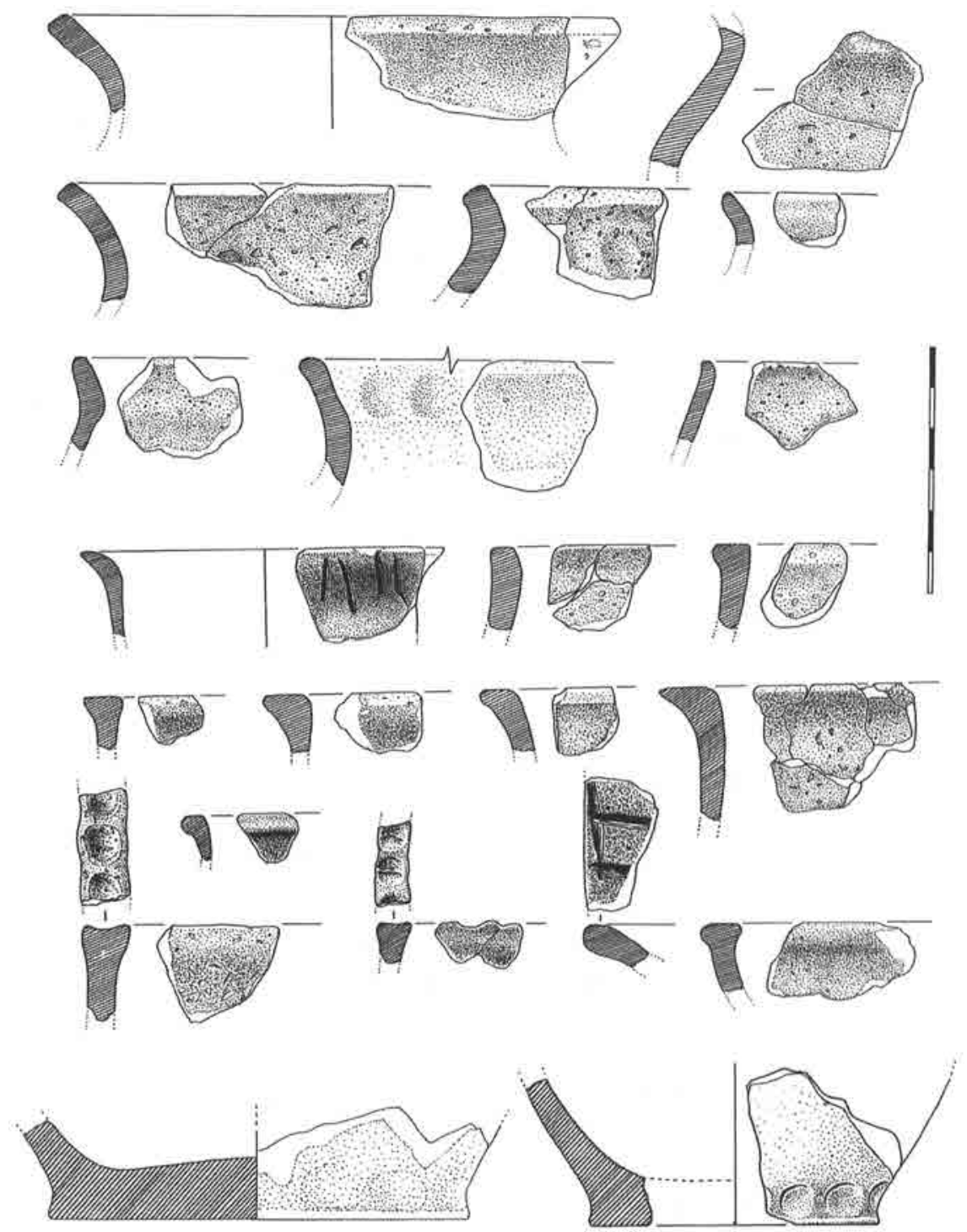

FIG. 18. Cerámica del castro de Castilnegro (según Valle y Serna, 2003).

a. C., al igual que sucede con el castro de Castilnegro,

datado entre los ss. VI-II a. C., y con el castro de Argüeso-Fontibre, adscrito a la Primera Edad del Hierro a partir de las características morfotipológicas de la cerámica.

A partir de la segunda mitad del I milenio a. C. los rasgos morfológicos y decorativos anteriormente citados comienzan a convivir con otros nuevos. Se da paso así a una producción caracterizada por una mayor variabilidad en la que empiezan a ser representativos los elementos de prensión, las decoraciones impresas con estampillados e incisas complejas y, a partir del s. IV a. C., la cerámica oxidante a torno, ocasionalmente pintada (Cubas et al., 2013).

Este esbozo de la cerámica de la Primera Edad del Hierro en Cantabria y, en concreto, para el castro del Alto de La Garma no es exclusivo del territorio cántabro, sino que es extensible a los territorios colindantes donde, si por algo debemos caracterizarlos, es también por la falta de información disponible (Peñalver, 2001; Marín, 2012). En toda la 

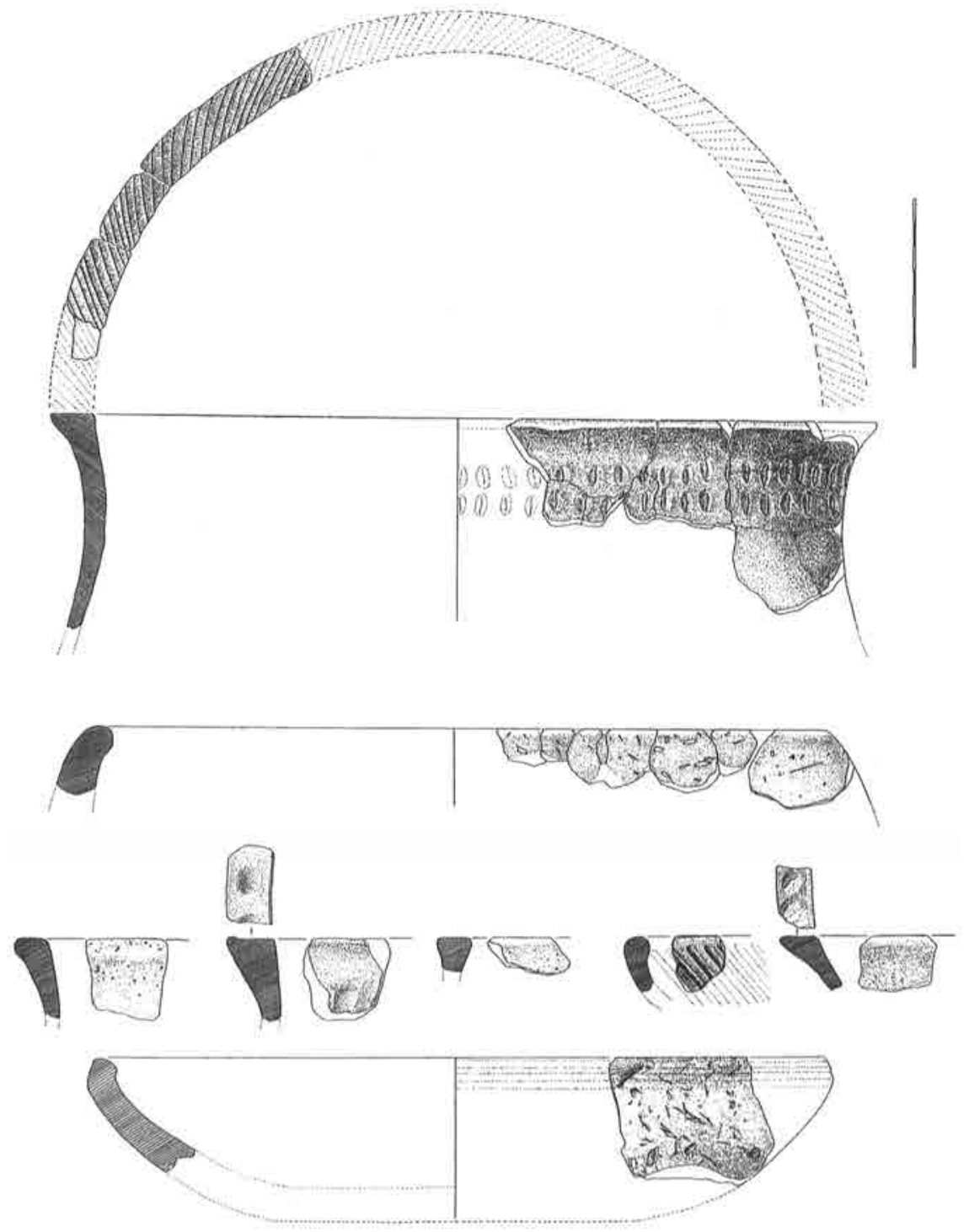

Fig. 19. Cerámica del castro de Castilnegro (según Valle y Serna, 2003).

No obstante, a pesar de los pocos fragmentos conservados, la decoración a base de digitaciones e incisiones en los labios nos lleva a pensar en las reminiscencias de una herencia procedente de la Edad del Bronce, que parece ser común en el sector central del Cantábrico (Marín, 2012), y que incluso se puede apreciar hasta en época romana. Podemos destacar en este sentido las cerámicas incisas localizadas en la Campa Torres (Gijón, Asturias) procedentes de niveles datados en los ss. VI-V a. C. (Maya y Cuesta, 2001), los bordes digitados de los castros de Intxur (AlbizturTolosa, Guipúzcoa) y de Buruntza (Guipúzcoa) (Peñalver, 2001), los bordes con incisiones y ungulaciones de los yacimientos de Brizuela (Burgos) y Valtierra de Albacastro (Burgos) (Bohigas, 1986-1987), los hallados en El Viso (Lodosa, Navarra) (García et al., 1983; Armendáriz y Mateo, 2002-2003) o los recientemente exhumados, con ungulaciones e incisiones, en el oppidum de Monte Bernorio (Villarén, Palencia) (Torres, 2007). Estos últimos proceden de un yacimiento inmerso en

Cordillera Cantábrica y en la Meseta Norte carecemos de estudios sistemáticos sobre las producciones cerámicas prerromanas, debiendo acudir, cuando es posible, a los hallazgos procedentes de distintos yacimientos, lo que, unido a la escasa representatividad de nuestra muestra, hace que, a nivel interregional, no podamos, por el momento, decir más que el que estamos ante una producción que podría relacionarse con los modelos productivos propuestos para el mundo prerromano en el occidente de Asturias (Marín, 2007). lo que posteriormente será considerado territorio cántabro, mostrando una clara relación con las producciones referidas de Castilnegro, Argüeso-Fontibre, el Ostrero y el Alto de La Garma.

\section{Valoración y conclusiones}

La información disponible en la actualidad no permite llevar a cabo una caracterización de las primeras fases de la secuencia de manufactura 
cerámica en el Alto de La Garma. Esto, unido al desconocimiento de las estructuras destinadas a su cocción, nos impide reconocer si nos encontramos ante producciones locales o productos elaborados en otros asentamientos.

Las producciones cerámicas documentadas en el Alto La Garma están realizadas a mano, lo que nos permite situar la ocupación del castro en un momento previo a la introducción del torno en la región, lo que es coherente con las dataciones disponibles.

Existen algunos rasgos que denotan una cierta estandarización en la producción cerámica, como la morfología de los bordes, entre los que destacan los de direccionalidad exvasada y morfología plana, y la recurrencia observada en los motivos decorativos. Rasgos similares se han documentado en otros sitios arqueológicos del período, como los castros de Argüeso-Fontibre y Castilnegro o el yacimiento al aire libre del Ostrero.

Respecto a la funcionalidad de los recipientes cerámicos, en el caso del Alto de La Garma es poco lo que sabemos debido al alto índice de fragmentación que impide reconstruir formas. No obstante, podemos resaltar la existencia de piezas destinadas al almacenaje y a la vida cotidiana y productos que delatan la existencia de actividades especializadas como los fragmentos de crisol, evidencias de la actividad metalúrgica que se estaba desarrollando en el poblado.

\section{Bibliografía}

Arias, P.; González Sáinz, C.; Moure, A. y Ontañón, R. (2000): "Estudio integral de Complejo Arqueológico de La Garma (Omońo, Ribamontán al Monte)”. En Ontañón, R. (ed.): Actuaciones arqueológicas en Cantabria 1984-1999. Santander: Consej. de Cultura y Deporte de Cantabria, pp. 271-277.

Arias, P. y Ontañón, R. (2008): “Estudio integral del complejo arqueológico de La Garma. 2000-2003”. En Ontañón, R. (coord.): Actuaciones arqueológicas en Cantabria 2000-2003. Santander: Consej. Cultura, Turismo y Deporte de Cantabria, pp. 43-60.

Arias, P.; Ontañón, R.; Cepeda, J. J.; Pereda, E. y CueTo, M. (2010): "Castro del Alto de la Garma (Omoño, Ribamontán al Monte)”. En Serna, L.; Martínez, A. y Fernández, V. (coords.): Castros y Castra en Cantabria. Fortificaciones desde los orígenes de la Edad del Hierro a las guerras con Roma. Catálogo, revisión y puesta al día. Santander: ACANTO, pp. 501-514.
Armendáriz, R. M. y Matero, M. R. (2002-2003): “Excavaciones en El Viso (Lodosa)", Trabajos de Arqueologia Navarra, 16, pp. 107-140.

Bohigas, R. (1986-1987): "La Edad del Hierro en Cantabria. Estado de la cuestión”, Zephyrus, xxxIX-XL, pp. 119-138.

Bronk, C. (2009): "Bayesian analysis of radiocarbon dates”, Radiocarbon, 51/1, pp. 337-360.

Calvo, M.; Fornés, J.; García Roselló, J.; Guerrero, V. M.; Juncosa, E.; Quintana, C. y Salvá, B. (2004): La cerámica prehistórica a mano: una propuesta para su estudio. Treballs d'Arqueobalear, 1. Mallorca: El Tall.

Cubas, M.; Bolado del Castillo, R.; Pereda, E. y Fernández Vega, P. (2013): "La cerámica en Cantabria desde su aparición (5000 cal BC) hasta el final de la Prehistoria: técnicas de manufactura y características morfo-decorativas", Munibe, 64, pp. 5-24.

Fernández Acebo, V.; Serna, M. L. y Muñoz FernánDEz, E. (2004): El macizo de Peña Cabarga. Un recorrido por el tiempo y el patrimonio. Santander: ACANTo, pp. 66-69.

García Ramírez, S.; Espinosa, U. y García Écija, A. (1983): "Nuevos yacimientos de la Primera Edad del Hierro en el valle medio del Ebro (zona riojano-navarra)", Cuadernos de Investigación: Historia, t. 9, fasc. 1, pp. 81-94.

Lamalfa, C.; Muñoz Fernández, E.; San Miguel, C. y FERnÁndez IbÁŃEZ, C. (1996): "El yacimiento de El Ostrero (Alto Maliaño, Cantabria). Memoria de excavación”. En El final de la Prehistoria. Ocho Estudios sobre Protohistoria de Cantabria. Santander, pp. 141-156.

Marín, C. (2007): "Los materiales del castro de San Lluis (Allande, Asturias)", Complutum, 18, pp. 131-160.

Marín, C. (2012): "La cerámica de la Edad del Hierro en el sector centro-occidental cantábrico”, Munibe, 63, pp. 165-198.

Maya, J. L. y Cuesta, F. (2001): El castro de la Campa Torres. Periodo prerromano. Gijón.

Olaetxea, C. (2000): La tecnología cerámica en la protohistoria vasca. Munibe Supl., 12. San Sebastián.

Peñalver, X. (2001): El hábitat en la vertiente atlántica de Euskal Herria. El Bronce Final y la Edad del Hierro. Kobie Anejo, 3. Vizcaya.

Pereda, E. (1999): "El Alto de La Garma: un castro de la Edad del Hierro en el Bajo Miera”. En Iglesias, J. M. y Muñiz, J. A. (eds.): Regio Cantabrorum. Santander: Caja Cantabria, pp. 63-77.

Reimer, P.; Bard, E.; Bayliss, A.; Beck, J.; Blackwell, P.; Bronk Ramsey, C.; Grootes, P.; Guilderson, T.; Haflidason, H.; Haldas, I.; Hatté, C.; Heaton, T.; Hoffman, D.; Hogg, A.; Hughen, K.; Kaiser, K.; Kromer, B.; Manning, S.; Niu, M.; Reimer, R.; Richards, D.; Scotts, E.; Southon, J.; Staff, R.; TurNey, C. y VAN Der Plicht, J. (2013): "IntCal13 and Marine13 Radiocarbon Age Calibration Curves 0-50,000 years cal вр", Radiocarbon, 55/4, pp. 1869-1887. http://dx.doi.org/10.2458/azu_js_rc.55.16947 
Rice, P. M. (1987): Pottery analysis. A sourcebook. Chicago: Univ. of Chicago Press.

Ruiz Gutiérrez, A. (1999): "El castro de Argüeso-Fontibre (Hermandad de Campoo de Suso, Cantabria)". En Iglesias, J. M. y Muñız, J. A. (eds.): Regio Cantabrorum. Santander: Caja Cantabria, pp. 53-61.

Ruiz Gutiérrez, A. (2000): “El poblamiento prerromano en Cantabria: estudio arqueológico del castro de Argüeso-Fontibre (Hermandad de Campoo de Suso)". En Ontañón, R. (ed.): Actuaciones arqueológicas en Cantabria 1984-1999. Santander: Consej. de Cultura y Deporte de Cantabria, pp. 341-342

Ruiz Gutiérrez, A. (2007): "Arqueología e historia antigua en la Hermandad de Campoo de Suso", Cuadernos de Campoo, xiII, 48, pp. 16-24.

Ruiz Gutiérrez, A. (2010): "Castro de La Campana”. En Serna, L.; Martínez, A. y Fernández, V. (coords.): Castros y Castra en Cantabria. Fortificaciones desde los origenes de la Edad del Hierro a las guerras con Roma. Catálogo, revisión y puesta al día. Santander: ACANTO, pp. 363-368.

Ruiz Gutiérrez, A. (2011): "Acerca del origen de las fortificaciones en el sur de Cantabria: El castro de la Campana”, Castillos de España, 161-163, pp. 11-14.

Rye, O. S. (1994): Pottery technology: Principles and reconstruction. Manuals on Archaeology, 4. Washington: Taxacum.

Torres, J. F. (2007): "Monte Bernorio en su entorno. Resumen de los trabajos arqueológicos efectuados en la campaña de 2004”. En FAnjul, A. (coord.): Estudios varios de arqueología castreña. A propósito de las excavaciones en los castros de Teverga (Asturias). Santander: Ayto. de Teverga-IEPA, pp. 77-101.

VAlle, M.a A. (2000): "El poblamiento prehistórico en el arco sur de la bahía de Santander. El Alto del Gurugú”. En Ontañón, R. (ed.): Actuaciones arqueológicas en Cantabria 1984-1999. Santander: Consej. de Cultura y Deporte del Gobierno de Cantabria, pp. 355-356.

Valle, M.a A. (2008): "El poblamiento de la Edad del Hierro en el Castro de Castilnegro. Campañas 20002003”. En Ontañón, R. (coord.): Actuaciones arqueológicas en Cantabria 2000-2003. Santander: Consej. de Cultura, Turismo y Deporte del Gobierno de Cantabria, pp. 159-164.

Valle, M. a A. (2010): "Castro de Castilnegro (Medio Cudeyo-Liérganes)”. En Serna, L.; Martínez, A. y Fernández, V. (coords.): Castros y Castra en Cantabria. Fortificaciones desde los orígenes de la Edad del Hierro a las guerras con Roma. Catálogo, revisión y puesta al día. Santander: ACANTO, pp. 473-488.

Valle, M. a A. y Serna, M. L. (2003): "El Castro de Castilnegro y otros asentamientos de la Edad del Hierro en el entorno de la Bahía de Santander”. En Fernández Ibáñez, C. y Ruiz Coвo, J. (eds.): La Arqueología de la Bahia de Santander. Santander: Fund. Marcelino Botín, pp. 351-390.

VAN DEN Eynde, E. (2000): "Excavaciones en el castro de Peña Campana en Argüeso: campañas de 1990 y 1991”. En Ontañón, R. (ed.): Actuaciones arqueológicas en Cantabria 1984-1999. Santander: Consej. de Cultura y Deporte de Cantabria, pp. 171-172. 